\title{
Seasonal variation in acute hospital admissions and emergency room presentations among children in the Australian Capital Territory
}

\author{
Rennie M D'Souza, ${ }^{1}$ Hilary J Bambrick, ${ }^{1}$ Tord E Kjellstrom, ${ }^{1}$ Liza M Kelsall, ${ }^{2}$ Charles S Guest ${ }^{2}$ and Ivan Hanigan ${ }^{1}$ \\ ${ }^{1}$ National Centre for Epidemiology and Population Health, Australian National University and ${ }^{2}$ Population Health Division, ACT Health, The Canberra Hospital, \\ Canberra, Australian Capital Territory, Australia
}

\begin{abstract}
Aim: To examine seasonal variation in hospital use for five paediatric conditions of the Australian Capital Territory residents.
Methods: Hospital admissions (1993-2004) and emergency room (ER) presentations (1999-2004) for asthma, croup, bronchiolitis, other respiratory conditions and diarrhoea of children aged $<5$ years were compared by month and season.

Results: The five conditions comprised $14 \%$ of admissions and $24 \%$ of ER presentations of children aged $<5$ years. Bronchiolitis (both admissions and ER presentations) were the highest in the $0-1$ year age group (>80\%) and the other four conditions peaked at 1-2 years. Children aged $0-2$ years contributed $66 \%$ of diarrhoea, $62 \%$ of croup and $44 \%$ of other respiratory admissions whereas ER presentations were higher for other respiratory conditions (57\%) and lower for croup (47\%). Boys showed higher rates of admissions and ER presentations for all conditions except diarrhoea. Strong seasonal associations were apparent. Incident rate ratios of admissions were significantly higher in autumn compared with summer for asthma and croup whereas bronchiolitis and other respiratory conditions admissions were the highest in winter. Diarrhoea admissions were the highest in spring. ER presentations of the five conditions also showed similar associations with season.

Conclusion: Hospital admissions and ER presentations of these five conditions showed strong seasonal patterns, knowledge of which could contribute to improved resource planning (staffing) to meet expected increases in demand for services and scheduling of elective admissions. These findings could be extended to develop a model for forecasting hospital use and to explore the causes of these diseases to ameliorate seasonal effects.
\end{abstract}

Key words: asthma; bronchiolitis; children; diarrhoea; respiratory; seasonal variation.

Seasonal variation in mortality and acute hospital use in countries with temperate climates is particularly prominent in very young children (aged $<2$ years), ${ }^{1-4}$ and the elderly. ${ }^{5}$ Such variation in hospital admissions has previously been observed for influenza, respiratory syncytial virus (RSV), ${ }^{1}$ pneumonia $^{3}$ and

\section{Key Points \\ 1 Children under the age of 1 year had the highest admissions and emergency room presentations for bronchiolitis whereas those aged 1-2 years had the highest admissions and emer- gency room presentations for asthma, croup, other respiratory conditions and diarrhoea. \\ 2 There is strong seasonal variation in diarrhoea and respiratory paediatric hospital admissions and emergency room presentations. \\ 3 Boys showed higher rates of admissions and emergency room presentations for asthma, croup, bronchiolitis and other respi- ratory conditions compared with girls.}

Correspondence: Dr Rennie M D'Souza, National Centre for Epidemiology and Population Health, Australian National University, Canberra, ACT 0200, Australia. Fax: +61 26125 0740; email: rennie.dsouza@anu.edu.au

Accepted for publication 6 September 2006 diarrhoeal disease. ${ }^{2}$ During winter there is an increased incidence of influenza in Australia particularly in children under the age of 5 years. ${ }^{6}$ Childhood asthma also shows a seasonal variation for hospital emergency department attendances. ${ }^{7}$

Seasonal variation can assist in identifying potentially preventable determinants of these diseases. The excess number of presentations and admissions in certain seasons establishes the proportion of the burden of disease that might be preventable. Seasonal patterns of paediatric admissions have not been quantified in an Australian setting. The Australian Capital Territory (ACT) is known for its cold winters and hot dry summers, making it an excellent candidate in which to examine such seasonality. The objective of this paper is to describe, for children under 5 years, seasonal variation in hospital admissions and emergency room (ER) presentations by age and sex for asthma, croup, bronchiolitis, other respiratory conditions and diarrhoea in the ACT. This study also estimates the risks of increase in admissions and ER presentations from low to high seasons, providing information for scheduling services for diseases influenced by seasonal changes.

\section{Methods}

This is a population-based study of children under the age of 5 years who were residents of the ACT and hospitalised in The 
Canberra Hospital between January 1993 and December 2004 or who presented to the ER at either The Canberra Hospital or Calvary Hospital between January 1999 and December 2004 with diagnoses of asthma, croup, bronchiolitis, other respiratory conditions and diarrhoea. 'Other respiratory conditions' include the following conditions: influenza, pneumonia, acute upper respiratory infections (acute sinusitis, acute pharyngitis, acute tonsillitis, acute tracheitis, other unspecified conditions of upper respiratory tract, acute bronchitis and bronchiolitis) and other diseases of upper respiratory tract (allergic rhinitis, chronic sinusitis, chronic tonsillitis, peritonsillar abscess, chronic laryngitis and disease of vocal cords).

Re-admissions were not excluded and hospital admissions following an initial ER presentation were not linked in this study. Data for the study period were provided by the Information Management Unit of ACT Health and were grouped in disease categories according to International Classification of Diseases, 9th Revision and 10th Revision. Ethical approval for this study was obtained from the Australian National University Human Research Ethics Committee.

\section{Analysis}

The number of admissions and ER presentations by disease for each age group were calculated. Age- and sex-specific rates of admissions (1993-2004) and ER presentations (1999-2004) per 1000 population of children under 5 years of age for each disease condition were compared over the study period for years with complete data. The ACT population was interpolated for each year from the Estimated Resident Populations by Age and Sex for 1991, 1996, 2001, and estimated for 2002-2004. To display seasonal patterns, the 12 years of admission data and 6 years of ER presentations were aggregated into monthly totals for each disease category and were plotted.

To determine if certain seasons were associated with higher risks of hospitalisations and ER presentations, incident rate ratios (IRR) and 95\% confidence intervals (CIs) were calculated using a negative binomial regression model with summer as the reference group for each disease category. The months used for each season were: winter: June-August, spring: September-
November, summer: December-February and autumn: MarchMay.

\section{Results}

There were a total of 787388 admissions of the ACT residents to The Canberra Hospital between January 1993 and December $2004,11 \%(n=87371)$ of which were for children under the age of 5 years. Of these, $14.2 \%(n=12414)$ were for the following five conditions: other respiratory conditions, $5.1 \%$ $(n=4466)$; diarrhoea, $3.6 \% \quad(n=3147) ;$ asthma, $2.5 \% \quad(n=$ 2173); bronchiolitis, $1.9 \% \quad(n=1641)$; and croup, $1.1 \%$ $(n=987)$.

There were a total of 484735 ER presentations of the ACT residents to Canberra hospitals between January 1999 and December 2004, 12\% ( $n=58700)$ of which were for children under the age of 5 years. Of these, $24.4 \%$ were for the following five conditions: other respiratory conditions, 9.3\% $(n=5416)$; diarrhoea, 5.2\% $(n=3047)$; croup, $4.2 \%(n=2466)$; asthma, $3.4 \%(n=2003)$; and bronchiolitis, $2.3 \%(n=1362)$.

\section{Age distribution of admissions and ER presentations}

Admissions and ER presentations for bronchiolitis peaked in the $0-1$ year age group whereas the other four conditions peaked at 1-2 years and then declined (Fig. 1). Of hospital admissions, $66 \%$ of diarrhoea, $62 \%$ of croup, $44 \%$ of other respiratory conditions and $39 \%$ of asthma were for children under 2 years. Similarly for ER presentations, children under 2 years formed $62 \%$ of diarrhoea, $57 \%$ of other respiratory conditions, $47 \%$ of croup and $35 \%$ of asthma presentations (Fig. 1). Children under 1 year of age contributed to $84 \%$ and $82 \%$ of bronchiolitis admissions and ER presentations, respectively.

\section{Rates of admission and ER presentations}

The rate of admissions and ER presentations for asthma and croup declined over the study period for both boys and girls but a slight increase occurred in 2004 in admissions for other (a)

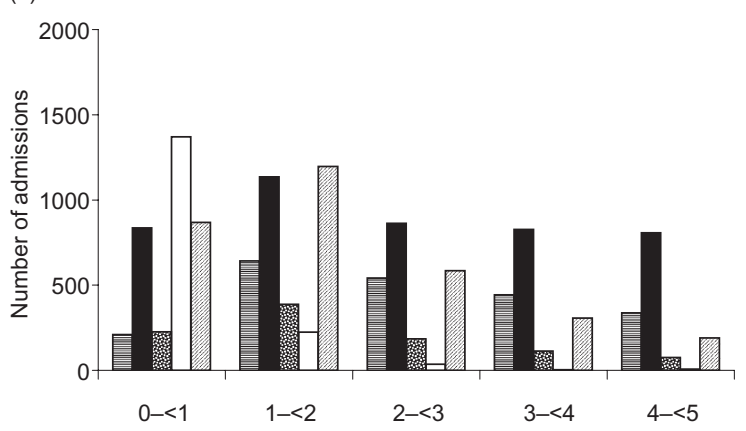

(b)

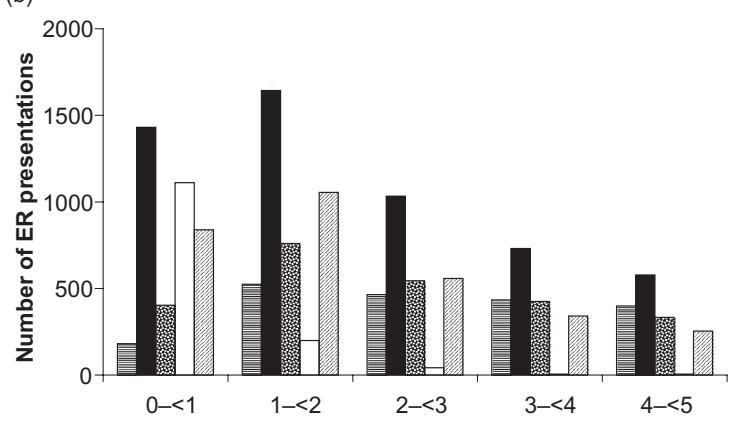

Fig. 1 Number of (a) hospital admissions (January 1993-December 2004) and (b) emergency room (ER) presentations (January 1999-December 2004) of children (0-4 years) in the Australian Capital Territory (ACT) by disease category and age group. Data sources: ACT Admitted Patient Care Collection, 19932004. ACT Emergency Department Information System 1999-2004. Confidential unit record files. (目) Asthma; ( $\mathbf{\square})$ other respiratory conditions; (

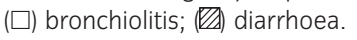


(a)

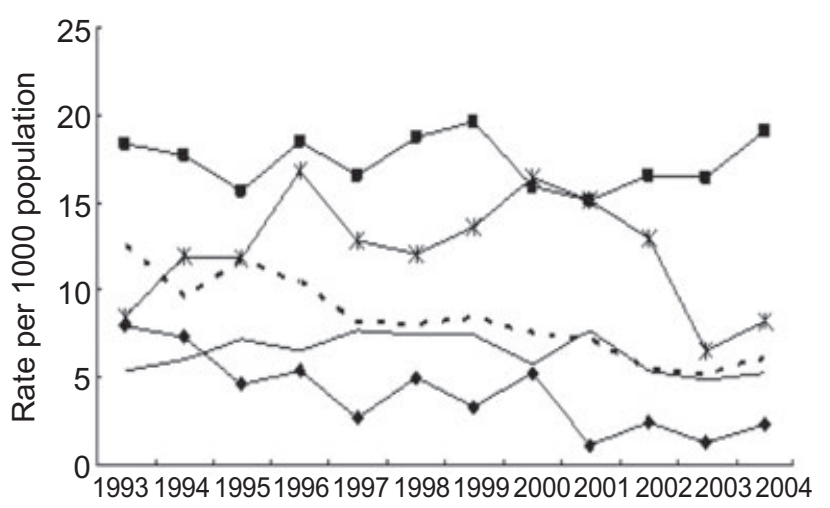

(b)

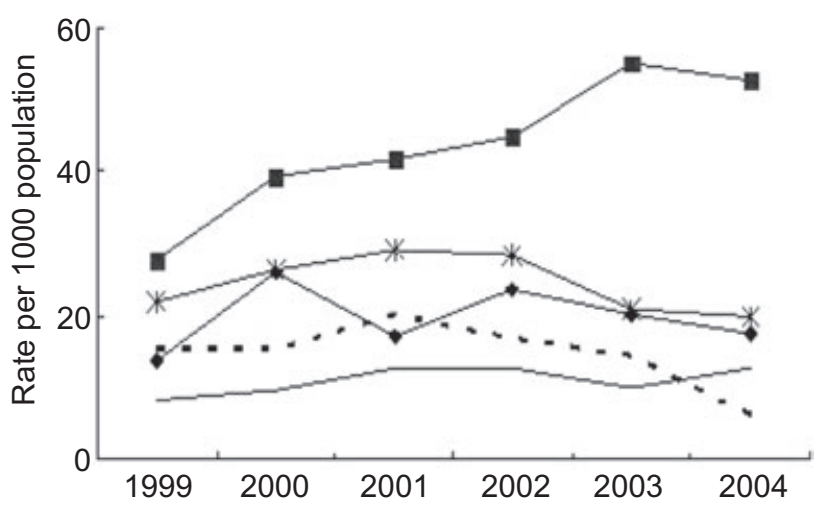

Fig. 2 Rates for (a) hospital admissions (January 1993-December 2004) and (b) emergency room presentations (January 1999-December 2004) of children (0-4 years) in the Australian Capital Territory (ACT). Data sources: ACT Admitted Patient Care Collection, 1993-2004. ACT Emergency Department Information System 1999-2004. Confidential unit record files. Other respiratory conditions; (- -) croup; (-) bronchiolitis; (- - - -) asthma; $(-)$ diarrhoea.

respiratory conditions and diarrhoea; and ER presentations for bronchiolitis (Fig. 2). ER presentations of other respiratory conditions increased steadily until 2003 and then plateaued. Bronchiolitis ER presentation appeared to peak every 3 years whereas croup admissions and ER presentations showed a biennial peak till 2002 (Fig. 2).

Admissions rates for diarrhoea fluctuated over the 12-year study period whereas ER presentations showed an increase until 2002 and then declined (Fig. 2). Boys had consistently higher rates of admissions and ER presentations than girls (except for diarrhoea), with the greatest difference occurring for asthma admissions and ER presentations of asthma, bronchiolitis and croup (data not shown). The admission and ER presentations followed the same pattern, even though the rates of ER presentations for asthma, bronchiolitis and diarrhoea were twice as high as rates of admission, and the rates of ER presentations for other respiratory conditions and croup were three and six times higher than the rate of admissions, respectively. (a)

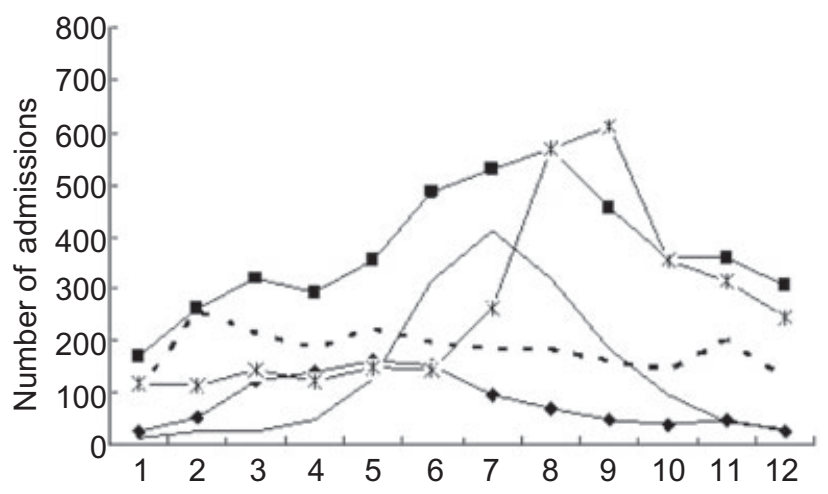

(b)

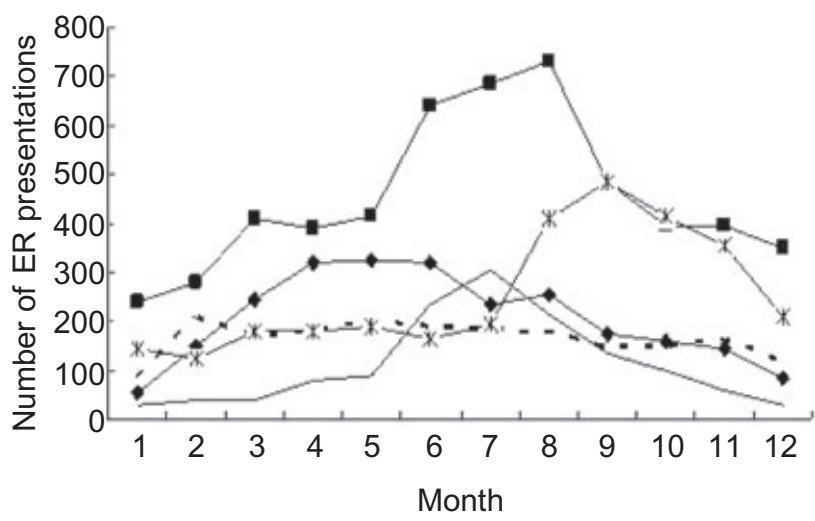

Fig. 3 The Australian Capital Territory (ACT) resident child (0-4 years) for (a) hospital admissions (January 1993-December 2004) and (b) emergency room (ER) presentations (January 1999-December 2004) for asthma, other respiratory conditions and diarrhoea, by month. Data sources: ACT Admitted Patient Care Collection, 1993-2004. ACT Emergency Department Information System 1999-2004. Confidential unit record files. (-口-) Other respiratory conditions; (-) croup; $(-)$ bronchiolitis; (- - - -) asthma; $(-x-)$, diarrhoea.

\section{Monthly variation in hospital admissions and ER presentations}

Hospital admissions and ER presentations for each age group were plotted by month of the year without adjustment for the number of days in the month (Fig. 3). As boys and girls showed similar patterns (data not shown) only the combined graphs are shown in Figure 3.

\section{Asthma}

Asthma had the highest number of admissions and ER presentations in February and the lowest in January (Fig. 3). Asthma admissions also peaked in May and October. The monthly pattern was not consistent across age groups for either admissions or ER presentations. Admissions and ER presentations of the 0to 1-year-olds showed a winter peak whereas children aged 12 years peaked in February and in winter (June/July) (data not shown). 


\section{Bronchiolitis, croup and other respiratory conditions}

Bronchiolitis admissions and ER presentations started to rise in April and peaked in July and then started to decline. The winter seasonal pattern for bronchiolitis admissions and ER presentations was very marked for children aged under 1 year and children aged 1-2 years also showed a similar winter pattern (data not shown). There were 46 admissions and ER presentations labelled as bronchiolitis in the older age groups but no pattern was discernible.

Admissions of children with croup showed an autumn peak. Admissions rose in March and peaked in May whereas ER presentations of croup increased from February and peaked in April, and then plateaued until June when they started to decline (Fig. 3). Hospital admissions and ER presentations of croup in under 1-year-olds peaked in June (data not shown).

Admissions and ER presentations for other respiratory conditions were the highest in winter months (July/August) (Fig. 3). Children aged 1-2 years showed the strongest winter peak followed by children aged 0-1 year and 2-3 years (data not shown).

\section{Diarrhoea}

Diarrhoea admissions and ER presentations peaked in September (Fig. 3). The pattern was consistent across age groups, with infants and children 1-2 years and 2-3 years showing the strongest seasonal pattern (data not shown).

\section{Seasonal patterns in hospital admissions and ER presentations and its association with season}

When hospital admissions and ER presentations were analysed by season, summer was the reference category. Asthma IRR for admissions (IRR $=1.29 ; 95 \%$ CI $1.08-1.53$ ) and ER presentations $\quad($ IRR $=1.34,1.08-1.67)$ were significantly higher in autumn compared with summer (Tables 1,2). ER presentations for asthma were also significantly higher in winter. IRRs of hospital admissions for other respiratory condition (IRR 2.14; 1.87-2.44) and ER presentations (IRR $=2.32 ; 2.01-2.69$ ) were significantly higher in winter compared with summer. IRRs for croup admissions (IRR $=3.88,2.77-5.42)$ and ER presentations $($ IRR $=3.07,2.33-3.97)$ were higher in autumn. IRRs for admissions and ER presentations of croup and other respiratory conditions were also significantly higher in winter and spring than summer. Analysis for bronchiolitis was restricted to children under the age of 2 years. Although bronchiolitis admissions and ER presentations had higher admissions in spring and autumn but admissions (IRR $=13.79 ; 9.60-19.82)$ and ER presentations $(\operatorname{IRR}=7.34 ; 5.23-10.29)$ were the highest in winter (Table 2$)$ compared with summer. Diarrhoea admissions were nearly three times higher in spring $(\operatorname{IRR}=2.73 ; 2.00-3.73)$ and twice as high in winter (IRR $=2.02 ; 1.48-2.77)$ compared with summer (Table 1). ER presentations for diarrhoea were the highest

Table 1 IRR and 95\% CI for the ACT resident child (0-4 years) hospital admissions (1993-2004) by season of the year and disease category

\begin{tabular}{|c|c|c|c|c|c|}
\hline Season & $\begin{array}{l}\text { Asthma } \\
\text { IRR }(95 \% \mathrm{CI})\end{array}$ & $\begin{array}{l}\text { Other respiratory conditions } \\
\text { IRR }(95 \% \mathrm{CI})\end{array}$ & $\begin{array}{l}\text { Croup } \\
\operatorname{IRR}(95 \% \mathrm{CI})\end{array}$ & $\begin{array}{l}\text { Bronchiolitis } \\
\operatorname{IRR}(95 \% \mathrm{CI})\end{array}$ & $\begin{array}{l}\text { Diarrhoea } \\
\operatorname{IRR}(95 \% \mathrm{CI})\end{array}$ \\
\hline Summer & 1.00 & 1.00 & 1.00 & 1.00 & 1.00 \\
\hline Autumn & $1.29(1.08-1.53)^{*}$ & $1.31(1.14-1.50)^{\star \star *}$ & $3.88(2.77-5.42)^{\star *}$ & $2.71(1.85-3.98)^{\star * *}$ & $0.89(0.64-1.22)$ \\
\hline Winter & $1.18(0.99-1.40)$ & $2.14(1.87-2.44)^{\star \star \star}$ & $3.12(2.22-4.38)^{\star \star}$ & $13.79(9.60-19.82)^{\star *}$ & $2.02(1.48-2.77)^{\star *}$ \\
\hline Spring & $1.08(0.91-1.29)$ & $1.58(1.38-1.81)^{\star *}$ & $1.39(0.97-2.01)$ & $4.45(3.06-6.47)^{\star *}$ & $2.73(2.00-3.73)^{\star *}$ \\
\hline
\end{tabular}

*Significant at $<0.01 ; * \star$ Significant at $<0.001$. Cl, confidence intervals; IRR, incident rate ratios. Data sources: Australian Capital Territory (ACT) Admitted Patient Care Collection, 1993-2004. Confidential unit record files.

Table 2 IRR and 95\% CI for ACT resident child (0-4 years) ER presentations (1999-2004), by season of the year and disease category

\begin{tabular}{|c|c|c|c|c|c|}
\hline Season & $\begin{array}{l}\text { Asthma } \\
\operatorname{IRR}(95 \% \mathrm{CI})\end{array}$ & $\begin{array}{l}\text { Other respiratory conditions } \\
\text { IRR }(95 \% \mathrm{Cl})\end{array}$ & $\begin{array}{l}\text { Croup } \\
\operatorname{IRR}(95 \% \mathrm{Cl})\end{array}$ & $\begin{array}{l}\text { Bronchiolitis } \\
\text { IRR ( } 95 \% \mathrm{CI})\end{array}$ & $\begin{array}{l}\text { Diarrhoea } \\
\text { IRR }(95 \% \text { CI) }\end{array}$ \\
\hline Summer & 1.00 & 1.00 & 1.00 & 1.00 & 1.00 \\
\hline Autumn & $1.34(1.08-1.67)^{*}$ & $1.40(1.21-1.63)^{\star \star}$ & $3.07(2.37-3.97)^{\star \star *}$ & $2.05(1.44-2.94)^{\star *}$ & $1.15(0.87-1.51)$ \\
\hline Winter & $1.33(1.07-1.66)^{*}$ & $2.32(2.01-2.69)^{\star *}$ & $2.76(2.13-3.58)^{\star \star}$ & $7.34(5.23-10.29)^{\star \star}$ & $1.63(1.25-2.14)^{\star \star}$ \\
\hline Spring & $1.14(0.91-1.43)$ & $1.38(1.19-1.61)^{\star \star}$ & $1.67(1.28-2.18)^{\star \star}$ & $2.83(1.99-4.02)^{\star \star}$ & $2.70(2.07-3.54)^{\star *}$ \\
\hline
\end{tabular}

*Significant at $<0.01$; **Significant at $<0.001$. Cl, confidence intervals; ER, emergency room; IRR, incident rate ratios. Data sources: Australian Capital Territory (ACT) Emergency Department Information System 1999-2004. Confidential unit record files. 
in spring compared with summer $(\operatorname{IRR}=2.70 ; 2.07-3.54)$ (Table 2).

\section{Discussion}

\section{Age- and sex-dependent variations}

Age was a significant factor that determined hospital admissions and ER room presentations but age-specific patterns varied by disease. Children aged under 2 years contributed to $57 \%$ of the admissions and ER presentations for the five conditions reviewed in this paper. As expected, children under the age of 1 year had the highest number of admissions and ER presentations for bronchiolitis whereas children aged 1-2 years had the highest number of admissions and ER presentations for other respiratory conditions, croup, diarrhoea and asthma. The high number of hospital admissions and ER presentations for other respiratory conditions in children aged less than 1 year is possibly due to some of the bronchiolitis cases in under 1-year-olds being misclassified as upper respiratory tract infections or viral illness, which would be included in our 'other respiratory conditions' category. Bronchiolitis is usually a diagnosis made in children aged less than 1 year, and its misdiagnosis as asthma may have contributed to the winter asthma peak observed in children aged under 1 year. This might also explain the differences between age groups in observed seasonal peaks, with service use among the youngest children diagnosed with asthma peaking during winter, perhaps reflecting different aetiology of wheeze, such as from RSV infection, or from misdiagnosis. Children aged more than 2 years who were diagnosed as bronchiolitis may be a coding error or misdiagnosis of these cases.

Being male was a risk factor for hospitalisation and ER presentation. Boys consistently showed higher rates than girls in all age groups for all diseases except diarrhoea, where no difference was observed between boys and girls. We cannot explain why boys are at greater risk for these conditions but this has been observed previously for asthma admissions in Ireland, ${ }^{8}$ and elsewhere in Australia, ${ }^{9}$ whereas in Finland, boys had higher rates of hospitalisation only in the summer but had lower rates than girls in winter. The different patterns found in the Finnish study may be due to the differences in age groupings between studies (under 15 years rather than under 5). ${ }^{10}$

\section{Seasonal pattern of hospital admissions}

\section{Asthma}

The seasonal pattern observed for asthma in children aged over 1 year has been observed in other parts of Australia in association with grass pollen. ${ }^{11}$ Exacerbations of asthma are sometimes caused by high concentrations of allergenic particles produced by an outflow of colder air, associated with the downdraught from a thunderstorm. ${ }^{12-14}$ Similar seasonal patterns of asthma have been documented in other countries, including New Zealand, ${ }^{15}$ Finland ${ }^{10}$ and Norway. ${ }^{16}$ The seasonality of asthma admissions has been attributed to a number of factors such as changes in temperature and humidity, ${ }^{17}$ wet season, tree and grass pollen, ${ }^{18}$ aeroallergens, ${ }^{19}$ viral infections, ${ }^{16}$ seasonal variation of fungal spores and house dust mite. ${ }^{20}$ Although these factors are not identical between countries, similar seasonal patterns are nevertheless observed.

The greatest number of asthma admissions and ER presentations occur in February, coinciding with the commencement of the school year after the long summer break, possibly promoting an increase in viral infections that precipitate acute asthma episodes. ${ }^{16}$ Although this seasonal pattern has been found previously in school-going children, the same pattern was observed in the under 5 years age group in the ACT. The most common cause of acute asthma exacerbations is rhinovirus, ${ }^{16}$ which may easily spread between students and their younger siblings when school reopens, resulting in higher incidence of asthma exacerbations even in younger, preschool-aged children. ${ }^{21}$ Similarly, such viruses could also be shared among young children in day care recommencing after the summer holidays.

We also hypothesise that the decrease in hospital admissions for asthma during school holidays occurs as people spend more time outdoors and there is consequently a decrease in the transmission of viruses that may trigger an episode. Further, summer is the peak holiday season and many families leave the ACT for vacation. This may be a factor for decreased hospital admissions and ER presentations of children resident in the ACT at this time. Furthermore, parents' capacity to care for their children is probably the greatest over the school holidays and they may pay more attention to their children's preventative asthma medication during the holidays. Lower level of stress in children during school holidays has also been suggested to play some role in the reduction of asthma morbidity at these times. ${ }^{10}$

\section{Croup, bronchiolitis and other respiratory conditions}

Admissions and ER presentations of bronchiolitis and other respiratory conditions increased in winter and decreased in summer whereas croup showed an autumn peak in the 1- to 2 -year-olds and a winter peak in the 0 - to 1 -year-olds. Bronchiolitis ER presentations appear to peak every 3 years in the ACT whereas croup showed more of a biennial pattern. A similar biennial mid-autumn peak and annual summer trough for croup in a 14-year study period were also found in Canada. $^{22}$

Respiratory syncytial virus is the most common pathogen identified in children with bronchiolitis. ${ }^{23}$ The cooler weather in winter forces people to spend more time indoors, a reason that outbreaks of RSV infections among very young children are observed in winter months. ${ }^{24}$ During winter as many as 50 $90 \%$ of children admitted with bronchiolitis may be infected with RSV. ${ }^{23}$ Influenza and RSV were the leading causes of paediatric admissions during the winter season in Japan and Greece, ${ }^{1,25,26}$ and in Japan, asthma was found to be a predominant underlying factor in those with influenza. ${ }^{1}$

The infections caused by RSV are seasonal, peaking predictably in the winter months ${ }^{25,26}$ in temperate climates, and in the hottest months and the rainy season in tropical climates. ${ }^{25-27}$ The seasons in which RSV epidemics occur typically depend on geographic location and altitude. Onset weeks and durations of RSV seasons vary substantially by year and location. ${ }^{28}$ During peak seasons the epidemics tend to appear in clusters. ${ }^{29}$ In the 
tropics, seasonal variations in the incidence of RSV infection are evident, with an annual peak in November, December and January. ${ }^{30}$

In New Zealand, the winter peaks of pneumonia admissions in children under 15 years of age was found to coincide with peaks in respiratory viral isolates and influenza type $\mathrm{A} \cdot{ }^{31} \mathrm{~A}$ recent review of possible explanations for the seasonality of respiratory tract viral infections concluded that there is a remarkable lack of knowledge and hypotheses about why these infections exhibit a seasonal variation. ${ }^{32}$ Perhaps seasonal exposure to cold air cooling of the nasal airway and an inhibition of respiratory defences against infection are contributing factors. Weber et al. found that two-thirds of hospitalised cases of lower respiratory infection were caused by RSV and the incidence was higher during cold seasons in areas with temperate climate and during wet seasons in tropical countries. ${ }^{33}$ However, a study of 2 - to 5-year-old children in the UK found only weak evidence of a relationship between cold indoor temperature and 'wheezy chest' and no relationship with upper respiratory tract infections. ${ }^{34}$ They highlighted the role of dampness as a cofactor with low temperature.

\section{Diarrhoea}

The spring peak observed for hospital admissions and ER presentations in the ACT are most probably due to rotavirus infections, which is the major cause of severe gastroenteritis in young children and has a high morbidity. ${ }^{35,36}$ In Australia, a seasonal trend of diarrhoea was observed in temperate regions with notable peaks in mid to late winter. ${ }^{37}$ The rate of acute gastroenteritis was 15 per 1000 in those under 5 years, $50 \%$ of which were attributable to rotavirus infection. The corresponding rates for rotavirus infection was 11.6 per 1000 for children aged less than 2 years. ${ }^{37}$ Other studies have estimated the proportion of hospital admissions of children under 5 years of age attributable to rotavirus in the range of 30 $66 \% .^{35,38}$

\section{Conclusion}

Based on the results of this study, the autumn, winter and spring peak in hospital admissions and ER presentations for the five conditions can be anticipated by estimating the excess number of admissions that would occur in three seasons (highservice-use periods) when compared with summer (lowservice-use period). How environmental exposures - both indoor and outdoor - change between seasons and their role in causing this variation in disease incidence in young children is not well understood and needs to be investigated. Several climatic factors (such as temperature and humidity), other climate-related factors (moulds and pollens) and behavioural factors (time spent indoors or peer interaction creating opportunities for infection) may be involved and could be acting synergistically. That there are a number of countries where seasonal patterns have been observed but without apparent consistency with climate suggests that behavioural and other factors may be more important.

An improved understanding of the seasonality of hospital admissions and which seasonally recurring factors drive or influence health service use would be useful in hospital management for improved service planning and providing care for these patients. 'Winter bed crisis' is a common feature of public hospitals. ${ }^{39,40}$ A reallocation of resources in terms of increasing staff and hospital beds could be undertaken in winter, as compared with summer, to meet the expected increase in demand for paediatric services. In addition, less elective surgery could be scheduled to accommodate anticipated increases in patient load over the winter months. Physicians, surgeons and bed managers could be brought together to plan elective admissions based on acute admissions. ${ }^{39}$ Potentially preventing excess admission is a further goal, but requires more understanding of the seasonal mechanisms. Targeted preventive policies that result in a reduction in hospital admissions for young children ${ }^{41}$ would achieve a major economic saving for hospitals and health departments, and reduce the burden of disease among this vulnerable group.

\section{Acknowledgements}

We thank the Information Management Unit of ACT Health for providing hospitalisation and ER presentation data. We also acknowledge Associate Professor Graham Reynolds from The Canberra Hospital for commenting on the draft manuscript. Financial support for this project was provided by ACT Health and the National Centre for Epidemiology and Population Health (NCEPH), The Australian National University. RMD and HJB were funded by NCEPH through a National Health and Medical Research Council (NHMRC) 'Capacity building grant, Environment and Population Health: Research Development from Local to Global, 2003-2007 (No. 224215).

\section{References}

1 Sugaya N, Mitamura K, Nirasawa M et al. The impact of winter epidemics of influenza and respiratory syncytial virus on paediatric admissions to an urban general hospital. J. Med. Virol. 2000; 60: 1026.

2 Ford-Jones EL, Wang E, Petric M et al. Hospitalization for communityacquired, rotavirus-associated diarrhea: a prospective, longitudinal, population-based study during the seasonal outbreak. The Greater Toronto Area/Peel Region PRESI Study Group. Pediatric Rotavirus Epidemiology Study for Immunization. Arch. Pediatr. Adolesc. Med. 2000; 154: 578-85.

3 Saynajakangas $\mathrm{P}$, Keistinen T, Tuuponen T. Seasonal fluctuations in hospitalisation for pneumonia in Finland. Int. J. Circumpolar Health 2001; 60: 34-40.

4 Viera SE, Stewien KE, Queiroz DAO et al. Clinical patterns and seasonal trends in respiratory syncytial virus hospitalizations in São Paulo, Brazil. Rev. Inst. Med. trop. Sao Paulo. [Online] 2001; 43: 125-31. Available from: http://www.scielo.br/scielo.php?script=sci_arttext\&pid=S003646652001000300002\&lng=en\&nrm=iso [accessed 9 May 2004].

5 Hider $\mathrm{P}$, Helliwell $\mathrm{P}$, Ardagh $\mathrm{M}$ et al. The epidemiology of emergency department attendances in Christchurch. N. Z. Med. J. 2001; 114: 1579.

6 National Notifiable Disease Surveillance System. 2002. Available from: http://www9.health.gov.au/cda/Source/Rpt_3.cfm [accessed 10 May 2004].

7 Kimes D, Levine E, Timmins S et al. Temporal dynamics of emergency department and hospital admissions of pediatric asthmatics. Environ. Res. 2004; 94: 7-17. 
8 Abduelrhman EM, Loftus BG. Paediatric asthma admissions in Galway 1985-89. Ir. Med. J. 1992; 85: 136-7.

9 Fleming DM, Cross KW, Sunderland R et al. Comparison of the seasonal patterns of asthma identified in general practitioner episodes, hospital admissions, and deaths. Thorax 2000; 55: 662-5.

10 Harju T, Keistinen T, Tuuponen T et al. Seasonal variation in childhood asthma hospitalisations in Finland, 1972-1992. Eur. J. Pediatr. 1997; 156: 436-9.

11 Green BJ, Dettmann M, Yli-Panula E et al. Atmospheric Poaceae pollen frequencies and associations with meteorological parameters in Brisbane, Australia: a 5-year record, 1994-1999. Int. J. Biometeorol. 2004; 48: 172-8.

12 Marks GB, Correll PK, Williamson M. Asthma in Australia 2005. Med. J. Aust. 2005; 183: 445-6.

13 Marks GB, Colquhoun JR, Girgis ST et al. Thunderstorm outflows preceding epidemics of asthma during spring and summer. Thorax 2001; 56: 468-71.

14 Girgis ST, Marks GB, Downs SH et al. Thunderstorm-associated asthma in an inland town in south-eastern Australia. Who is at risk? Eur. Respir. J. $2000 ; 16: 3-8$.

15 Kimbell-Dunn M, Pearce N, Beasley R. Seasonal variation in asthma hospitalizations and death rates in New Zealand. Respirology 2000; 5: 241-6.

16 Carlsen KH, Orstavik I, Leegaard J et al. Respiratory virus infections and aeroallergens in acute bronchial asthma. Arch. Dis. Child. 1984; 59 310-15.

17 Beer SI, Kannai YI, Waron MJ. Acute exacerbation of bronchial asthma in children associated with afternoon weather changes. Am. Rev. Respir. Dis. 1991; 144: 31-5.

18 Rosas I, McCartney HA, Payne RW et al. Analysis of the relationships between environmental factors (aeroallergens, air pollution, and weather) and asthma emergency admissions to a hospital in Mexico City. Allergy 1998; 53: 394-401.

19 Dales RE, Dann T, Burnett RT. Influence of outdoor aeroallergens on hospitalization for asthma in Canada. J. Allergy Clin. Immunol. 2004; 113: 303-6.

20 van der Heide S, de Monchy JG, de Vries K et al. Seasonal variation in airway hyperresponsiveness and natural exposure to house dust mite allergens in patients with asthma. J. Allergy Clin. Immunol. 1994; 93: 470-5.

21 Storr J, Lenney W. School holidays and admissions with asthma. Arch. Dis. Child. 1989; 64: 103-7.

22 Segal AO, Crighton EJ, Moineddin R et al. Croup hospitalizations in Ontario: a 14-year time-series analysis. Pediatrics 2005; 116: 51-5.

23 Glezen WP, Taber LH, Frank AL et al. Risk of primary infection and reinfection with respiratory syncytial virus. Am. J. Dis. Child. 1986; 140: 543-6.

24 Denny FW, Clyde WA Jr. Acute lower respiratory tract infections in nonhospitalized children. J. Pediatr. 1986; 108 (5 Pt 1): 635-46.
25 Tsolia MN, Kafetzis D, Danelatou K et al. Epidemiology of respiratory syncytial virus bronchiolitis in hospitalized infants in Greece. Eur. J. Epidemiol. 2003; 18: 55-61.

26 Kristensen K, Dahm T, Frederiksen PS et al. Epidemiology of respiratory syncytial virus infection requiring hospitalization in East Denmark. Pediatr. Infect. Dis. J. 1998; 17: 996-1000.

27 Law BJ, Carbonell-Estrany X, Simoes EA. An update on respiratory syncytial virus epidemiology: a developed country perspective. Respir. Med. 2002; 96 (Suppl. B): S1-7.

28 Mullins JA, Lamonte AC, Bresee JS et al. Substantial variability in community respiratory syncytial virus season timing. Pediatr. Infect. Dis. J. 2003; 22: 857-62.

29 Stensballe LG, Devasundaram JK, Simoes EA. Respiratory syncytial virus epidemics: the ups and downs of a seasonal virus. Pediatr. Infect. Dis. J. 2003; 22 (2 Suppl.): S21-32.

30 Chan PW, Chew FT, Tan TN et al. Seasonal variation in respiratory syncytial virus chest infection in the tropics. Pediatr. Pulmonol. 2002; 34: 47-51.

31 Grant CC, Scragg R, Tan D et al. Hospitalization for pneumonia in children in Auckland, New Zealand. J. Paediatr. Child Health 1998; 34 355-9.

32 Eccles R. An explanation for the seasonality of acute upper respiratory tract viral infections. Acta Otolaryngol. 2002; 122: 18391.

33 Weber MW, Mulholland EK, Greenwood BM. Respiratory syncytial virus infection in tropical and developing countries. Trop. Med. Int. Health 1998; 3: 268-80.

34 Ross A, Collins M, Sanders C. Upper respiratory tract infection in children, domestic temperatures, and humidity. J. Epidemiol. Community Health 1990; 44: 142-6.

35 Glass RI, Kilgore PE, Holman RC et al. The epidemiology of rotavirus diarrhea in the United States: surveillance and estimates of disease burden. J. Infect. Dis. 1996; 174 (Suppl. 1): S5-11.

36 Ferson MJ. Hospitalisations for rotavirus gastroenteritis among children under five years of age in New South Wales. Med. J. Aust. 1996; 164: 273-6.

37 Carlin JB, Chondros P, Masendycz P et al. Rotavirus infection and rates of hospitalisation for acute gastroenteritis in young children in Australia, 1993-1996. Med. J. Aust. 1998; 169: 252-6.

38 Spence L, Singer O, Kibsey P et al. Rotavirus infection in children with diarrhoea admitted to a general hospital in Metro Toronto. Can. J. Public Health 1985; 76: 17-20.

39 Fullerton KJ, Crawford VLS. The winter bed crisis - quantifying seasona effects on hospital bed usage. QJM 1999; 92: 199-206.

40 Vasilakis C, El-Darzi E. A simulation study of the winter bed crisis. Health Care Manag. Sci. 2001; 4: 31-6.

41 Blaisdell CJ, Weiss SR, Kimes DS et al. Using seasonal variations in asthma hospitalizations in children to predict hospitalization frequency. J. Asthma 2002; 39: 567-75. 